\title{
Erratum to: Adolescent Psychotherapy Outcomes in Community Mental Health: How Do Symptoms Align with Target Complaints and Perceived Change?
}

Veronika Karpenko • Julie Sarno Owens

Published online: 23 October 2012

(C) Springer Science+Business Media New York 2012

Erratum to: Community Ment Health J

DOI 10.1007/s10597-012-9515-0

The below acknowledgement text was inadvertently not published in the original article.

Acknowledgments This project was funded by a grant from the Ohio Department of Mental Health, Office of Program Evaluation and Research.

The online version of the original article can be found under doi:10.1007/s10597-012-9515-0.

V. Karpenko ( $\square)$

University of Central Oklahoma, Edmond, OK, USA

e-mail: karpenko.veronika@gmail.com

J. S. Owens

Ohio University, Athens, OH, USA

e-mail: owensj@ohio.edu 